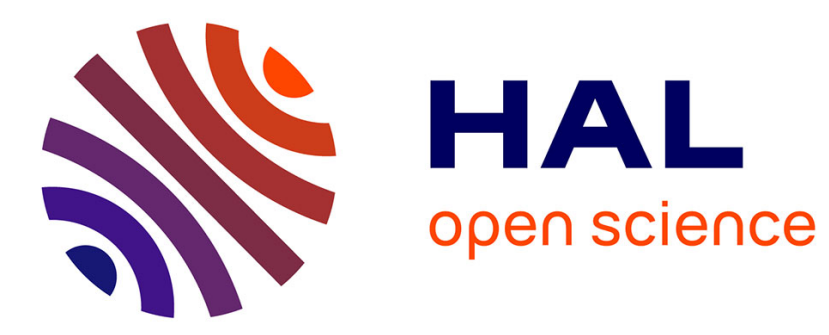

\title{
Magnetic Saturation Effects on the Control of a Synchronous Reluctance Machine
}

Thierry Lubin, Hubert Razik, Abderrezak Rezzoug

\section{To cite this version:}

Thierry Lubin, Hubert Razik, Abderrezak Rezzoug. Magnetic Saturation Effects on the Control of a Synchronous Reluctance Machine. IEEE Transactions on Energy Conversion, 2002, 17 (3), pp.356-362. hal-00556409

\section{HAL Id: hal-00556409 \\ https://hal.science/hal-00556409}

Submitted on 1 May 2015

HAL is a multi-disciplinary open access archive for the deposit and dissemination of scientific research documents, whether they are published or not. The documents may come from teaching and research institutions in France or abroad, or from public or private research centers.
L'archive ouverte pluridisciplinaire HAL, est destinée au dépôt et à la diffusion de documents scientifiques de niveau recherche, publiés ou non, émanant des établissements d'enseignement et de recherche français ou étrangers, des laboratoires publics ou privés. 


\title{
Magnetic saturation effects on the control of a synchronous reluctance machine
}

\author{
Thierry Lubin, Hubert Razik, Member, IEEE, and Abderrezak Rezzoug, Member, IEEE
}

\begin{abstract}
Experimental results on the magnetic saturation effects on the control of a small synchronous reluctance machine $(600 W)$ are presented in this paper. A new model of the machine, including saturation effects and cross magnetization is first developed. An approach based on total and mutual inductances is followed instead of the traditional approach via magnetizing and leakage inductances. All the electrical and mechanical parameters measurement required for the simulations are given. A rotororiented vector control of the synchronous reluctance machine is achieved with a DSP board (TMS320C31) and experimental results are presented. When the magnetic circuit is saturated, the simulation with the developed model shows a good accuracy of the results when they are compared to the experimental ones.
\end{abstract}

Index Terms - synchronous reluctance machine, saturation, vector control.

\section{NOMENCLATURE}

usd, usq: $\quad \mathrm{d}$ - and q-axis stator voltages,

isd, isq: $\quad \mathrm{d}$ - and q-axis stator currents,

ia, ib: d- and q- axis damper currents,

$\Psi_{\text {sd, }} \Psi_{\text {sq: }} \quad$ d- and q-axis total stator flux linkages,

$\Psi$ rd, $\Psi$ rq: $\quad$ d- and q-axis total rotor flux linkages,

Rs, Rr: $\quad$ stator and rotor resistances,

Ld, Lq: $\quad \mathrm{d}$ - and q-axis stator unsaturated inductances,

LD, LQ: $\quad \mathrm{d}$ - and q-axis rotor unsaturated inductances,

Md, Mq: $\quad \mathrm{d}$ - and q-axis unsaturated mutual inductances,

$\sigma d=1-\frac{M^{2}}{\text { Ld.LD }}: d$-axis total leakage coefficient,

$\sigma_{\mathrm{q}}=1-\frac{\mathrm{Mq}^{2}}{\mathrm{Lq} . \mathrm{LQ}}: \mathrm{q}$-axis total leakage coefficient,

$\mathrm{TD}=\frac{\mathrm{LD}}{\mathrm{Rr}}: \quad \mathrm{d}$-axis rotor time constant,

$\mathrm{TQ}=\frac{\mathrm{LQ}}{\mathrm{Rr}}: \quad \mathrm{q}$-axis rotor time constant,

we: $\quad$ electrical speed of the rotor reference frame,

p: number of pole pairs.

The authors are with the Groupe de Recherche en Electrotechnique et Electronique de Nancy, GREEN-CNRS UPRES-A 7037, Université Henri Poincaré, BP 239, 54506 Vandoeuvre-lès-Nancy Cedex, France (e-mail: thierry.lubin@green.uhp-nancy.fr).

\section{II.INTRODUCTION}

S known, an important part of electrical machines is $\mathbf{A}_{\text {made of ferromagnetic materials. These materials have }}$ non-linear magnetic characteristics. When the total magnetomotive force (which depends on the stator and rotor currents) in the machine increases, saturation of the ferromagnetic parts appears. The result of the saturation effects is a variation of the stator and rotor inductances. These parameters are used in the mathematical model of the machine and particularly in the electromechanical torque expressions. As a consequence, the control of the machine is drastically affected in terms of precision and dynamics.

A lot of researchers have studied the effects of magnetic saturation for a long time and have integrated it into the mathematical models of the electrical machines [1]-[14]. The generalized analytical treatments of the main flux saturation in the orthogonal axis models of smooth air-gap ac machines have first been developed in [1]-[3]. The influences of the saturation on the leakage inductances values have been investigated in [4]. Several authors have studied the consequence of saturation on the transient responses of a fieldoriented controlled induction machine [5]-[7]. For the synchronous reluctance machine (SynRM), different models have been proposed to take into account the effects of the magnetic saturation. The study developed in [8] have suggested a model using $d$ and $q$ saturation factors, which are a function of the flux in their respective axes. However, experimental results have shown the importance of the cross magnetizing effect in saturated synchronous machines [9] and the necessity to include this phenomenon in the mathematical representation of the synchronous reluctance machines [10][11]. The impacts of saturation on the performance of vector controls of synchronous reluctance motors are shown in [12][14] and in [20].

In this paper, experimental results of magnetic saturation effects on the control of a small synchronous reluctance machine $(600 \mathrm{~W})$ are presented. A new saturated model of the machine including only measurable parameters and using a single saturation factor is first developed. An approach based on total and mutual inductances follows in place of the traditional approach with magnetizing and leakage inductances. Electrical and mechanical parameters measurement required for the simulation are given. Using a DSP board (TMS320C31), a rotor-oriented vector control is achieved. Experiments are carried out for transient operations 
and are compared with the simulation in the case of both unsaturated and saturated conditions. The simulation show the importance of using a saturated model to obtain a good agreement of results when they are compared to the experimental ones.

\section{MODELING}

The cross section of the stator and rotor structure of the studied synchronous reluctance machine is shown in Fig. 1. The stator is made with symmetrical three phase windings and the rotor contains a squirrel cage. For the modeling, magnetic hysteresis, the skin effect (in the rotor bars) and iron losses are neglected. The air-gap magnetomotive forces are assumed to be sinusoidally distributed. The two-axis representation of the electrical equivalent machine is given in Fig. 2 .

The voltage equations of the two-axis representation written in the rotor reference frame are:

$$
\begin{aligned}
& \text { usd }=\text { Rs.isd }+\frac{d \Psi_{\text {sd }}}{d t}-\omega e . \Psi_{\text {sq }} \\
& u_{s q}=R_{s .} i_{s q}+\frac{d \Psi_{s q}}{d t}+\omega_{e} . \Psi_{s d} \\
& 0=\operatorname{Rr} \cdot i \mathrm{a}+\frac{\mathrm{d} \Psi \mathrm{rd}}{\mathrm{dt}} \\
& 0=\mathrm{Rr} . \mathrm{ib}+\frac{\mathrm{d} \Psi \mathrm{rq}}{\mathrm{dt}}
\end{aligned}
$$

The stator and rotor flux linkage in equations (1) to (4) are related to the currents as follows:

$$
\begin{aligned}
& \Psi_{\text {sd }}=\text { Ld.isd }+ \text { Md.ia } \\
& \Psi_{\text {sq }}=\text { Lq.isq }+ \text { Mq.ib } \\
& \Psi_{\text {rd }}=\text { LD.ia }+ \text { Md.isd } \\
& \Psi_{\text {rq }}=\text { LQ.ib }+ \text { Mq.isq }
\end{aligned}
$$

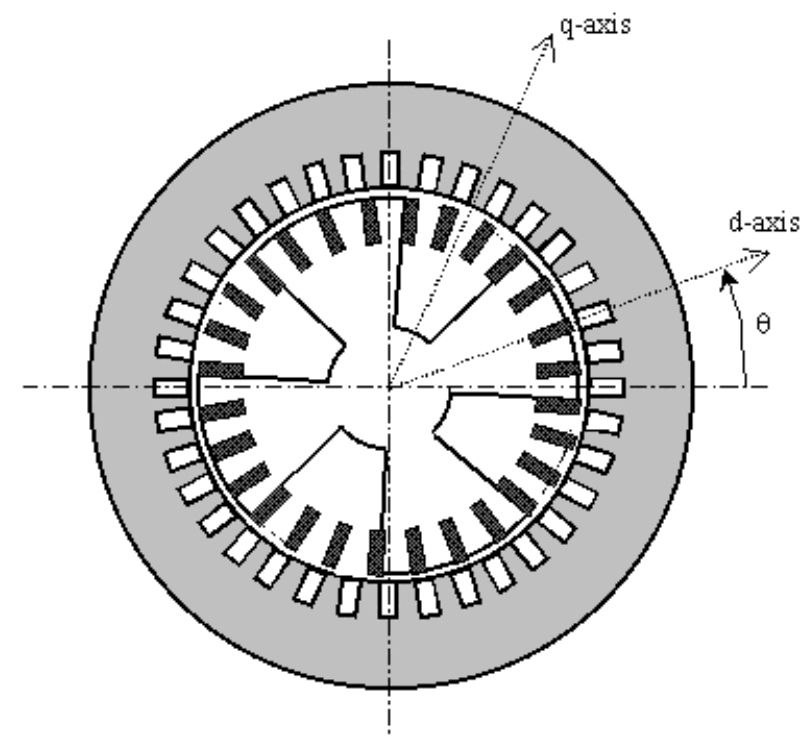

Fig.1 Cross section of the studied machine.

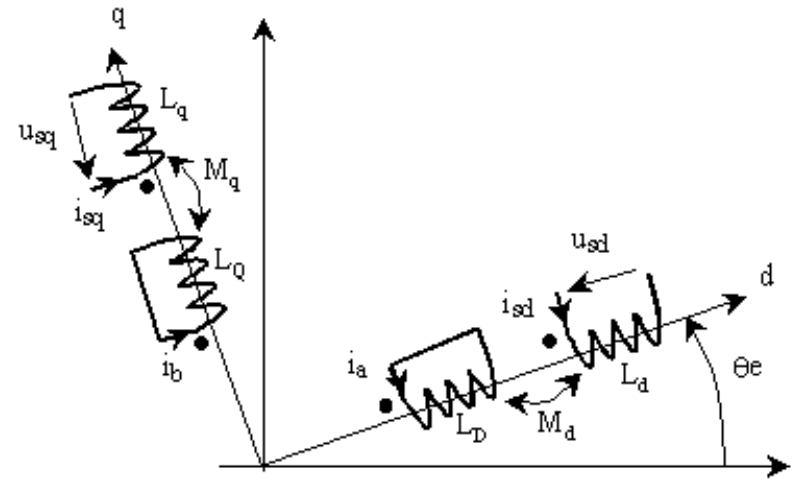

Fig. 2 Two-axis model in the rotor reference frame.

Introducing magnetizing currents Imd and Imq in the two axis, stator flux linkages become:

$\Psi_{\text {sd }}=$ Ld. Imd with $\operatorname{Imd}=i s d+\frac{M d}{L d} \cdot i a$
$\Psi_{s q}=$ Lq. Im q with $\operatorname{Imq}=i s q+\frac{M q}{L q} \cdot i b$

Usually, total inductances are split up into a leakage and a magnetizing component. Magnetizing inductance changes with the saturation level and the leakage one are supposed to remain constant. We don't make this distinction in this paper for several reasons. Firstly, we want to obtain a saturated model with only measurable parameters and we know that it is difficult to obtain stator and rotor leakage inductances separately by tests. Secondly, the hypothesis of constant leakage inductances with saturation is very disputable in ac machine as it is shown experimentally in [15].

A single factor saturation is used here to take into account the effects of magnetic saturation [16]. This saturation factor is a function of an equivalent magnetizing current obtained by converting an anisotropic machine into an equivalent isotropic one. This method has been applied in the case of main flux path saturation [10,17]. For the model that we develop, equivalent magnetizing current $\mathrm{Im}$ is defined as follows where $\mathrm{k}$ is the saliency factor.

$$
\begin{aligned}
& \mathrm{Im}=\sqrt{\mathrm{Im}^{2}+\mathrm{k}^{2} \cdot \operatorname{Imq}^{2}} \\
& \mathrm{k}=\sqrt{\frac{\mathrm{Lq}}{\mathrm{Ld}}}
\end{aligned}
$$

It is assumed that the d-axis and the q-axis inductances (total and mutual inductances) saturate to the same level under all operating conditions. The saturation factor $\mathrm{Ks}$ is defined by the ratio between saturated inductance and the unsaturated one.

$$
\mathrm{Ks}_{\mathrm{s}}(\mathrm{Im})=\frac{\mathrm{Ld}(\mathrm{Im})}{\mathrm{Ld}}=\frac{\mathrm{Lq}(\mathrm{Im})}{\mathrm{Lq}}
$$


By using the saturation factor defined above, we obtain the expressions of the saturated stator and rotor flux linkage (including cross magnetizing).

$\Psi_{\text {sd }}=\mathrm{Ks}_{\mathrm{s}}(\mathrm{Im}) \cdot \mathrm{Ld} . \mathrm{Imd}$

$\Psi_{\text {sq }}=K_{s}(\operatorname{Im}) \cdot$ Lq. Im q

$\Psi$ rd $=$ Md.Ird with $\operatorname{Ird}=K_{s}(\operatorname{Im}) \cdot\left\{\frac{1}{1-\sigma d} \cdot \operatorname{Imd}-\frac{\sigma d}{1-\sigma d} \cdot\right.$ isd $\}$

$\Psi r q=$ Mq. Irq with $\operatorname{Irq}=\operatorname{Ks}(\operatorname{Im}) \cdot\left\{\frac{1}{1-\sigma_{q}} \cdot \operatorname{Imq}-\frac{\sigma_{q}}{1-\sigma_{q}} \cdot\right.$ isq $\}$

Currents Ird and Irq defined in equations (16) and (17) are an image of the saturated rotor flux linkage and will be used next in this paper as state space variables.

Saturation factor variation can easily be measured from the no-load test or the d-c test at standstill [18]. The results obtained for the machine studied in this paper are shown in Fig. 3. As shown in [19], a close estimate for the saturation factor is obtained by using a rational fraction (18). The values of coefficients are given in the appendix.

$$
\mathrm{Ks}_{s}(\operatorname{Im})=\frac{1+\mathrm{a} \cdot \operatorname{Im}+\text { b. } \operatorname{Im}^{2}+\mathrm{c} \cdot \operatorname{Im}^{3}+\mathrm{d} \cdot \operatorname{Im}^{4}}{1+\text { e. } \operatorname{Im}+\text { f. } \cdot \operatorname{Im}^{2}+\text { g. } \operatorname{Im}^{3}+\text { h. } \cdot \operatorname{Im}^{4}}
$$

The new model of the saturated synchronous reluctance machine is given below. The choice of $\Psi_{\mathrm{sd}}, \Psi_{\mathrm{sq}}$, Ird and Irq as state-space variables allows to obtain a model where the first derivative of $\mathrm{Ks}_{\mathrm{s}}(\mathrm{Im})$ is not necessary and where parameters are all measurable thanks to classical tests. The unsaturated model is easily obtained with $\mathrm{K}_{\mathrm{s}}=1$

$$
\begin{aligned}
& \frac{\mathrm{d} \Psi_{\mathrm{sd}}}{\mathrm{dt}}=-\frac{\mathrm{Rs}}{\mathrm{Ks}_{\mathrm{s}} \sigma \mathrm{d} . \mathrm{Ld}} \cdot \Psi_{\mathrm{sd}}+\omega_{\mathrm{e}} \cdot \Psi_{\mathrm{sq}}+\frac{\mathrm{Rs} .(1-\sigma \mathrm{d})}{\mathrm{K}_{\mathrm{s} . \sigma \mathrm{d}}} \cdot \operatorname{Ird}+\mathrm{usd} \\
& \frac{\mathrm{d} \Psi_{\mathrm{sq}}}{\mathrm{dt}}=-\omega_{\mathrm{e}} \cdot \Psi_{\mathrm{sd}}-\frac{\mathrm{Rs}_{\mathrm{s}}}{\mathrm{Ks.} \sigma_{\mathrm{q} . \mathrm{Lq}}} \cdot \Psi_{\mathrm{sq}}+\frac{\mathrm{Rs}_{\mathrm{s} .}\left(1-\sigma_{\mathrm{q}}\right)}{\mathrm{Ks}_{\mathrm{s}} \sigma_{\mathrm{q}}} \cdot \operatorname{Irq}+\mathrm{usq}_{\mathrm{sq}}
\end{aligned}
$$

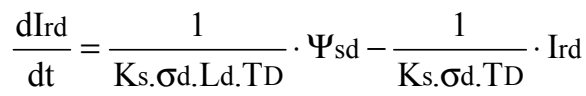

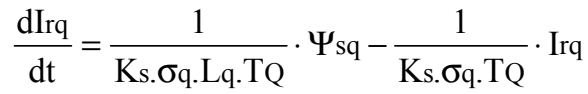

All the parameters which appear in equations (19) to (22) have been measured under unsaturated conditions [21] and are summarized in Table I.

TABLE I

UNSATURATED PARAMETERS VALUES

\begin{tabular}{|c|c|c|c|c|c|c|}
\hline $\mathbf{R s}$ & $\mathbf{L d}$ & $\boldsymbol{\sigma d}$ & $\mathbf{T D}$ & $\mathbf{L q}$ & $\boldsymbol{\sigma}_{\mathbf{q}}$ & $\begin{array}{c}\text { TQ } \\
(\Omega)\end{array}$ \\
\hline$(\mathrm{H})$ & $(\mathrm{s})$ & $(\mathrm{H})$ & & \\
\hline 7.8 & 0.54 & 0.056 & 0.1 & 0.21 & 0.2 & 0.046 \\
\hline
\end{tabular}

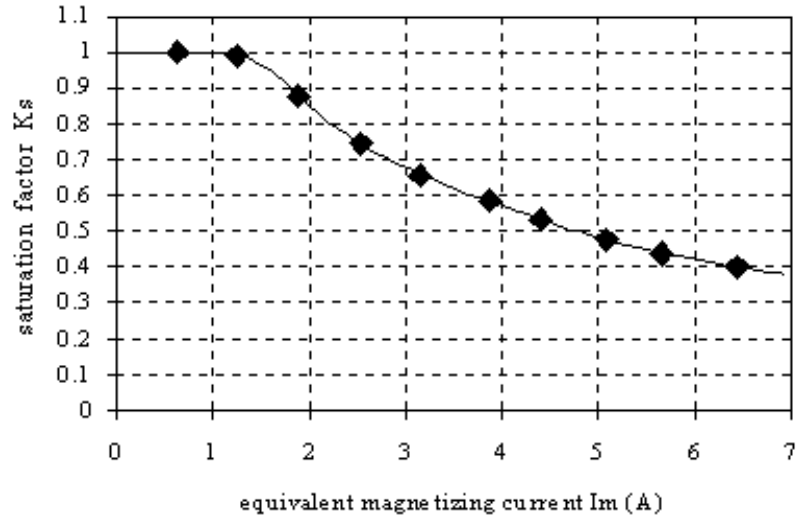

Fig. 3 Saturation factor of the studied machine.

The equation of motion and the expression of the electromechanical torque are written as:

$\mathrm{J} \cdot \frac{\mathrm{d} \Omega}{\mathrm{dt}}+\mathrm{f} \cdot \Omega=\mathrm{Tem}-\mathrm{Tr}$
$\mathrm{Tem}=\mathrm{p} \cdot\left(\Psi_{\mathrm{sd}}\right.$. isq $_{\mathrm{sq}}-\Psi_{\mathrm{sq}}$. isd $)$

where $\mathrm{J}$ is the moment of inertia, $\mathrm{f}$ the friction coefficient and $\operatorname{Tr}$ the load torque. The values of $\mathrm{J}$ and $\mathrm{f}$ are given in the appendix.

\section{CONTROL}

A functional block diagram of the synchronous reluctance machine vector control is given in Fig. 4. The SynRM is fed by a voltage-source PWM inverter. The control is achieved with a DSP board (TMS320C31). The constant d-axis current strategy is used [22]. Conventional PI controllers (25) are used for current loops (d-axis and q-axis current controllers) with a sample time of $200 \mu \mathrm{s}$.

$\mathrm{Cd}(\mathrm{z})=\mathrm{Kpd}+\frac{\mathrm{Kid}}{1-\mathrm{z}^{-1}}$ and $\mathrm{Cq}(\mathrm{z})=\mathrm{Kpq}+\frac{\mathrm{Kiq}}{1-\mathrm{z}^{-1}}$

The results of the calculation of the PI controllers gains are given in Table II. These controllers allow to obtain good dynamic performances for current loops (a response time of $3 \mathrm{~ms}$ in both $\mathrm{d}$-axis and q-axis current loops). For the speed loop, an IP controller with an integrator antiwindup is used. IP algorithm is executed to generate the needed Isqref current reference. The simulation algorithm is written in $\mathrm{C}$ language and we use a standard fourth-order Runge-Kutta integration routine.

TABLE II

VALUES OF THE CURRENT CONTOLLERS GAINS

\begin{tabular}{|c|c|c|c|}
\hline Kpd & Kid & Kpq & Kiq \\
\hline 40 & 6 & 52 & 7 \\
\hline
\end{tabular}




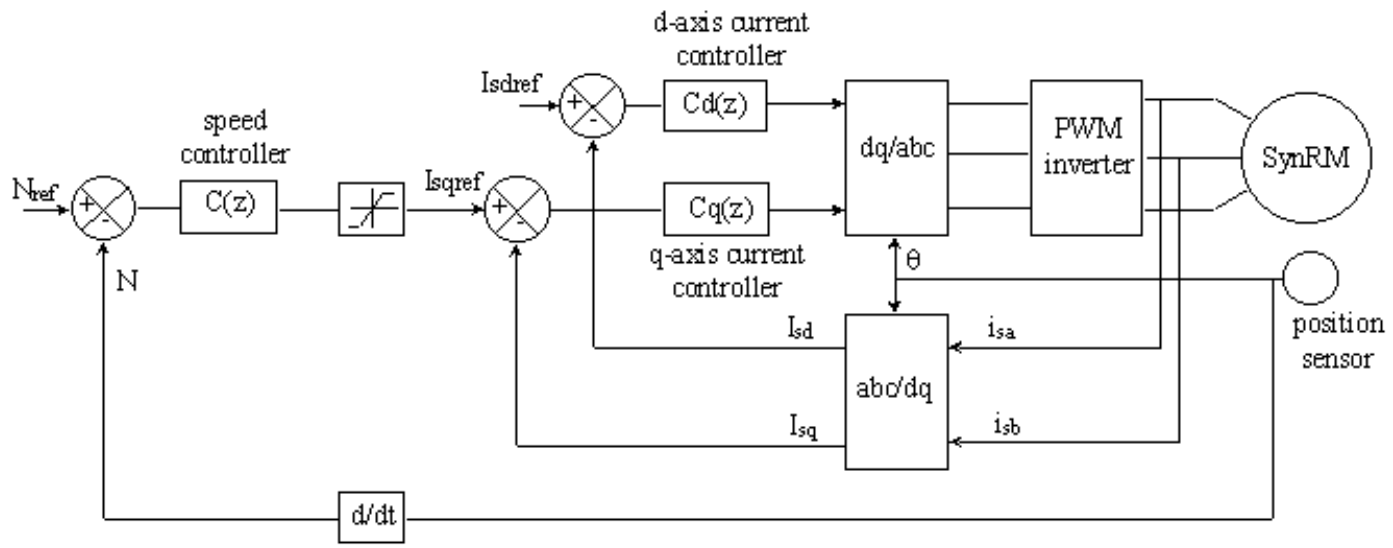

Fig. 4 Block diagram of the experimental system.

It is based on the saturated model developed in the first part. PWM inverter with dead time and current and speed controllers are included in the simulation.

To observe the effects of magnetic saturation on control and to compare the simulation results with the experimental ones, two transient operation tests have been made. One has been made under unsaturated conditions and the other under saturated conditions.

\section{A. Test under unsaturated conditions}

A first experimental test has been made under unsaturated conditions. Low values of Isd (Isdref $=1.5 \mathrm{~A}$ ) and Isq have been chosen (a small range of change in speed reference allows to
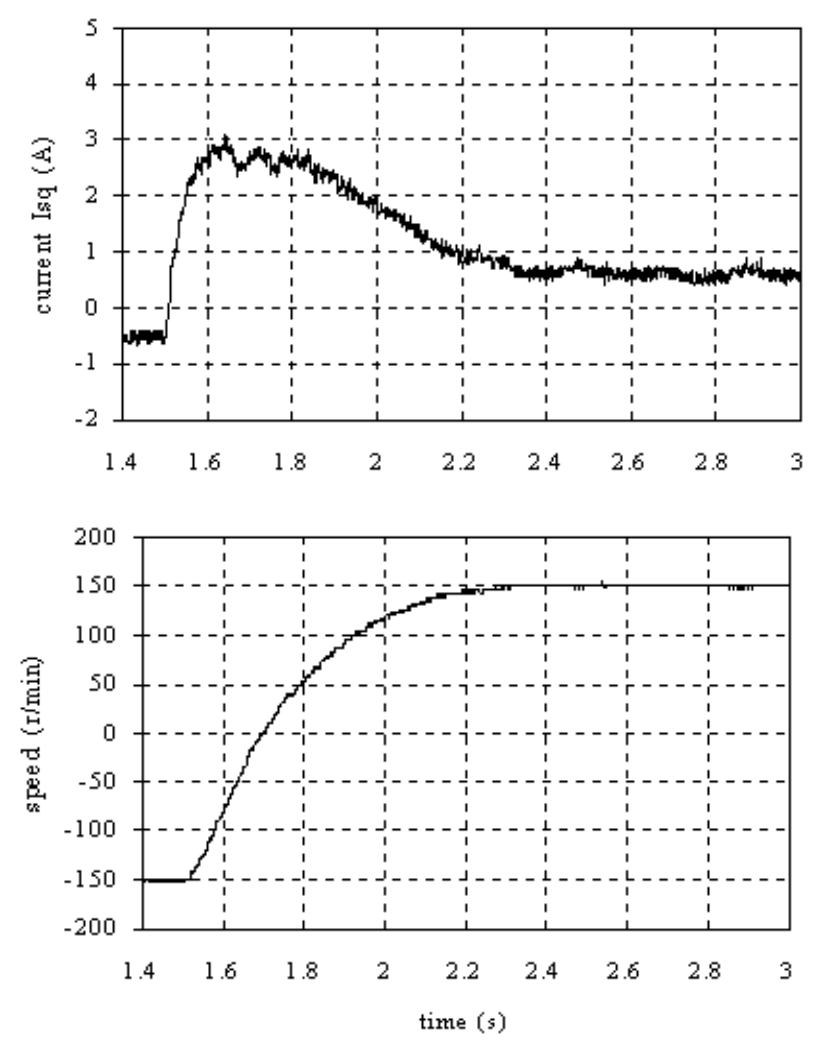

Fig. 5 Experimental results under unsaturated conditions. obtain a low value for Isq). Simulation tests have been made with both the saturated model by using $\mathrm{Ks}(\mathrm{Im})$ defined in equation (18) and the unsaturated one (by using $\mathrm{Ks}^{=1}$ ) and the same results have been obtained (Fig. 6 and Fig. 6b). Other simulation results have been obtained by using the unsaturated model with the value of the saturation factor that corresponds to the rated operating conditions $(\mathrm{Ks}=0.6)$.

The results of the experimental test for the q-axis current, the speed and the phase current are shown in Fig. 5 and Fig. $5 \mathrm{~b}$. We observe a good accuracy between the experimental and the simulation results (with $\mathrm{Ks}(\mathrm{Im})$ or $\mathrm{Ks}=1$ ). The speed, the q-axis current and phase current waveforms are almost the same in shape as predicted by simulation studies.
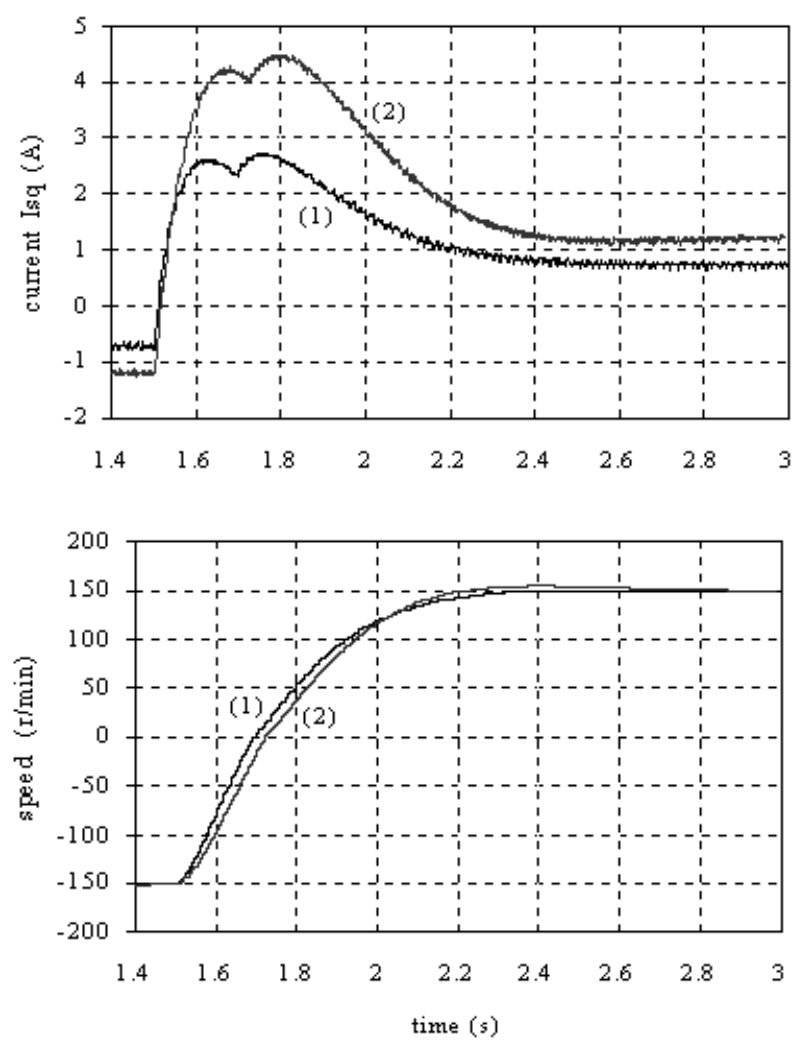

Fig. 6 Simulation results under unsaturated conditions: (1) saturated model and unsaturated model with $\mathrm{Ks}=1$, (2) unsaturated model with $\mathrm{Ks}=0.6$. 


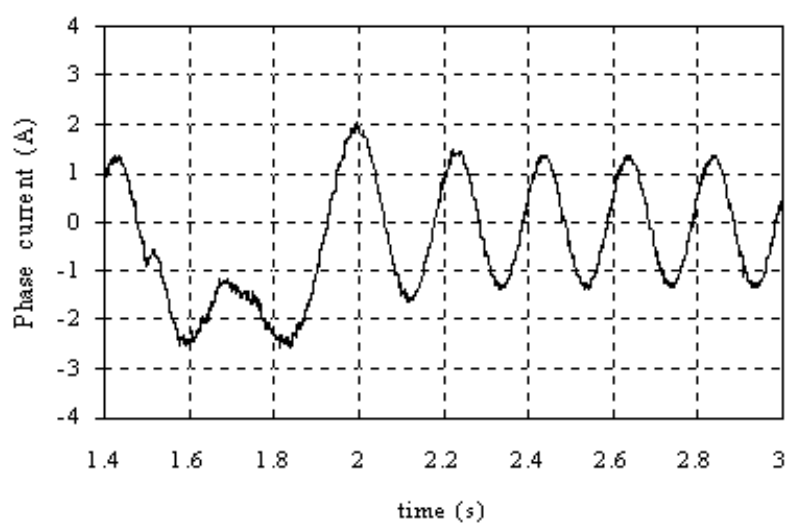

Fig. 5b Experimental results under unsaturated conditions.

The conclusion of this test is that under unsaturated conditions, both the classical model $(\mathrm{Ks}=1)$ and the saturated model of the synchronous reluctance machine are adequate to predict the dynamic responses (speed and q-axis current) of the control with a high precision.

\section{B. Test under saturated conditions}

The second experimental test has been made under saturated conditions. The value of Isd has been fixed to $2.5 \mathrm{~A}$ and the value of Isq is high (a large range of change in speed
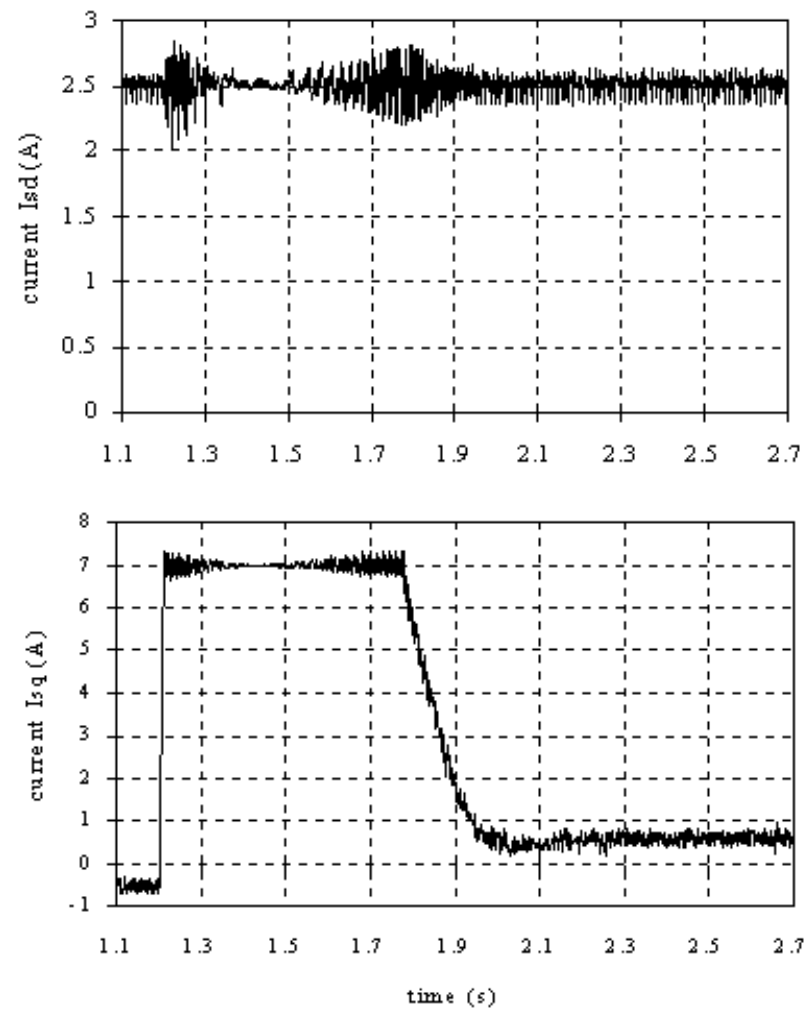

Fig. 7 Experimental results under saturated conditions.

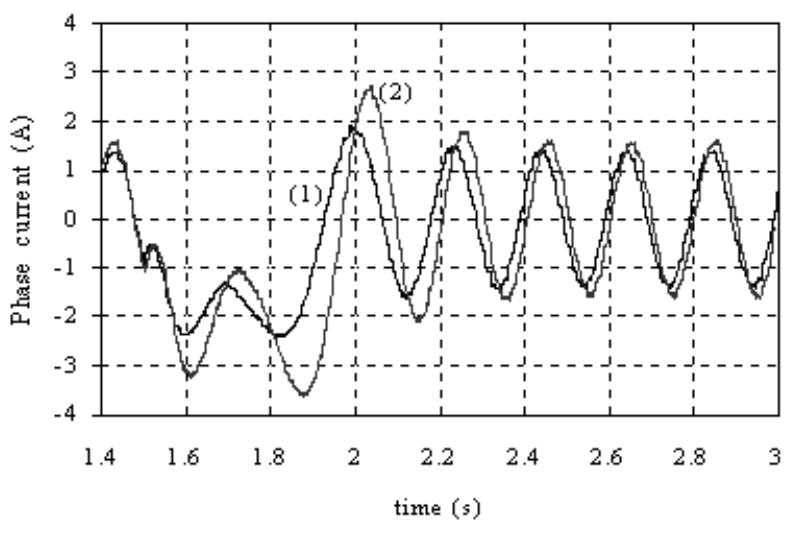

Fig. 6b Simulation results under unsaturated conditions: (1) saturated model and unsaturated model with $\mathrm{Ks}=1$, (2) unsaturated model with $\mathrm{Ks}=0.6$.

reference allows to obtain a high value for Isq). The results of the experimental test and of the simulation one for the d-axis current, the q-axis current, the speed and the phase current are given in Fig. 7 and Fig. $7 \mathrm{~b}$ and in Fig. 8 and Fig. $8 \mathrm{~b}$. We can observe important differences between experimental and simulation results when the unsaturated model is used $(\mathrm{Ks}=1)$. The essential main difference between the test and simulated waveforms is a longer time of the transient for the speed in the experimental results. This difference can be explained as the impact of the magnetic saturation on the torque value during the transient.
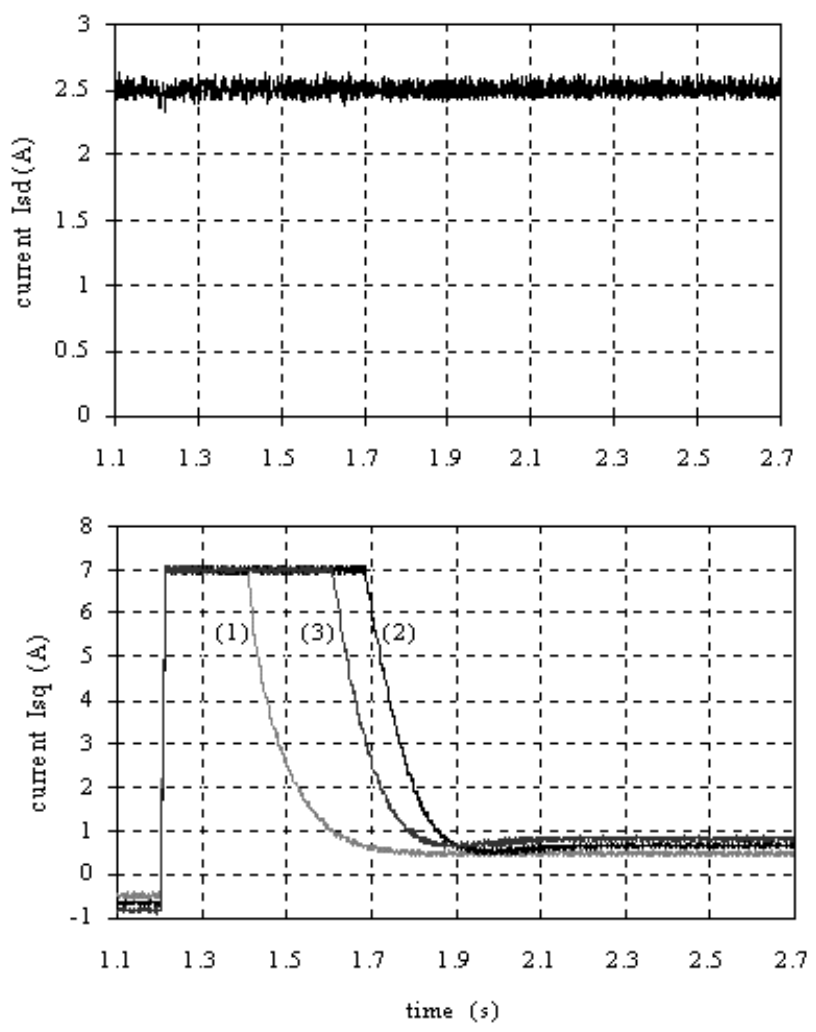

Fig. 8 Simulation results under saturated conditions: (1) unsaturated model with $\mathrm{Ks}=1$, (2) saturated model, (3) unsaturated model with $\mathrm{Ks}=0.6$. 

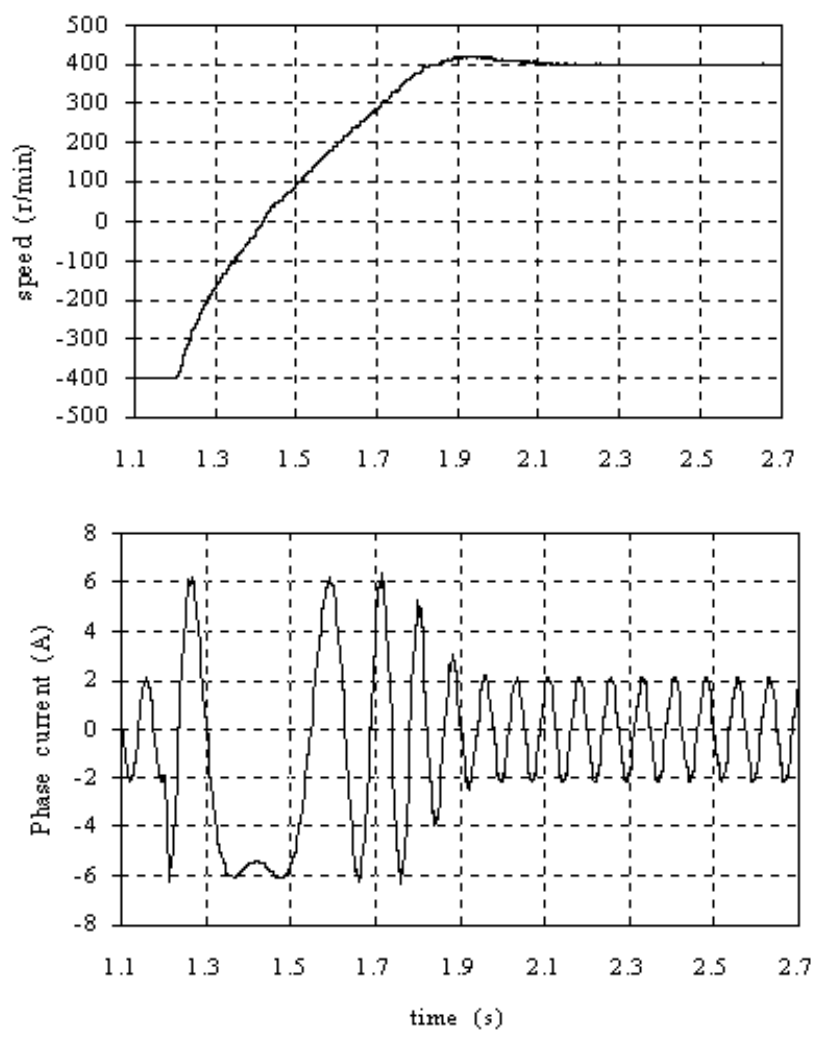

Fig. 7b Experimental results under saturated conditions.

Considering that damper winding currents ia and ib are equal to zero after a fast transient, the electromagnetic torque can be written as follows in (26). The value of Ks is estimated near to 0.48 (see Fig. 3) for this test and explains the differences.

$\mathrm{Tem}=\mathrm{Ks}(\mathrm{Im}) \cdot(\mathrm{Ld}-\mathrm{Lq}) \cdot \mathrm{Isd} \cdot \mathrm{Isq}$

As one can observe in Fig. 8 and in Fig. 8b, the use of the saturated model in the simulation gives a much better agreement of computed results with the experimental ones and justifies the model of the synchronous reluctance machine developed in the first part.

\section{V.SENSITIVITY ANALYSIS}

In order to show the influence of the saturation factor on simulation results, we are going to take the previous study with saturated conditions (Isdref $=2.5 \mathrm{~A}$ ) while modifying the value of the saturation factor slightly. To do that, we use two new saturation factors $\mathrm{Ks} 1(\mathrm{Im})$ and $\mathrm{Ks} 2(\mathrm{Im})$ defined below:

$\operatorname{Ks} 1(\operatorname{Im})=\frac{1.63}{1+0.504 . \operatorname{Im}}$ with $\operatorname{Im} \geq 1.25 \mathrm{~A}$

$\mathrm{Ks} 2(\operatorname{Im})=\frac{1.7}{1+0.466 . \operatorname{Im}}$ with $\operatorname{Im} \geq 1.5 \mathrm{~A}$
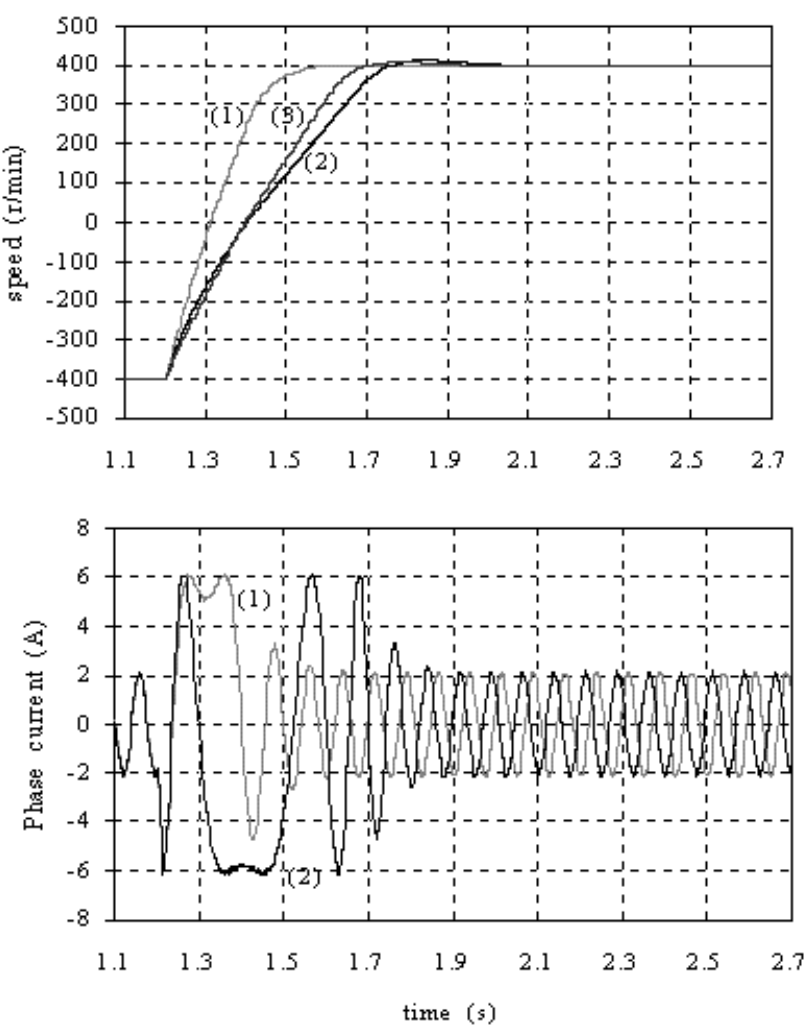

Fig. 8b Simulation results under saturated conditions: (1) unsaturated model with $\mathrm{Ks}=1$, (2) saturated model, (3) unsaturated model with $\mathrm{Ks}=0.6$.

The variations of these saturation factors with the equivalent magnetizing current are given in Fig. 9. We can observe that the new saturation factors allow to obtain a variation of the saturation curve around the one defined in the first part of this paper.

The simulation results obtained by using the saturated model with different saturation factors are displayed in Fig. 10. This test is made under saturated conditions with Isdref $=2.5 \mathrm{~A}$. One can observe that the transient responses on the speed and on the q axis current are close to each other and almost follow the uncertainty on the saturation factor .

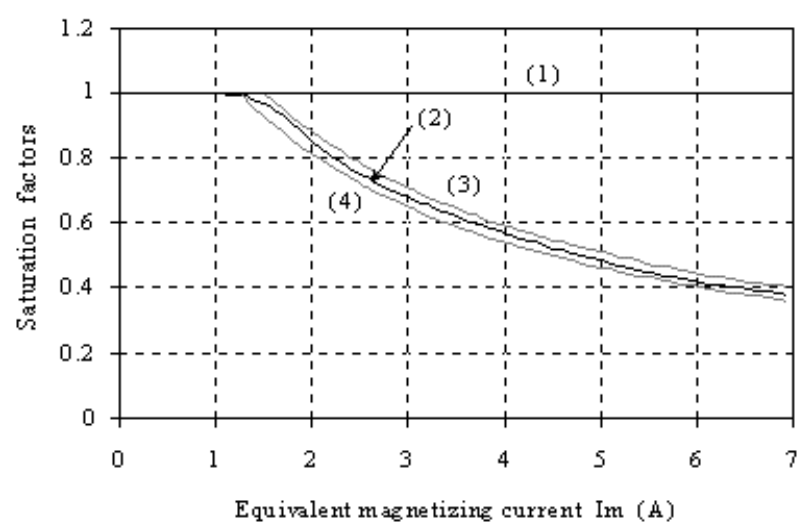

Fig. 9 Saturation Factors: (1) Ks=1, (2) Ks(Im), (3) Ks2(Im), (4) Ks1(Im). 

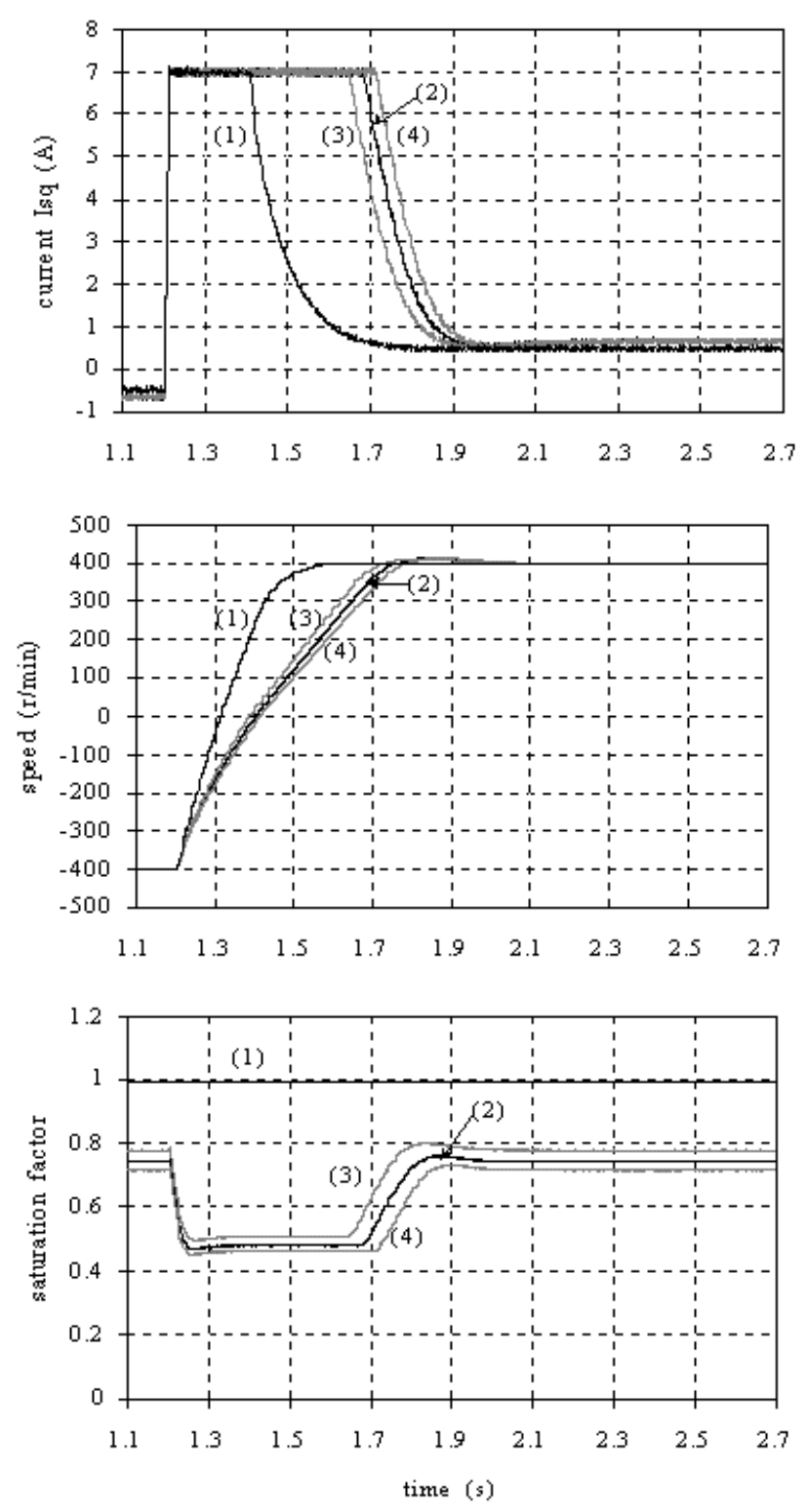

Fig. 10 Simulation results under saturated conditions: (1) unsaturated model with $\mathrm{Ks}=1$, (2) saturated model with $\mathrm{Ks}(\mathrm{Im})$, (3) saturated model with Ks2(Im), (4) saturated model with Ks1(Im),

\section{CONCLUSION}

Experimental results have shown the effects of the magnetic saturation on the vector control of a synchronous reluctance machine. Under saturated conditions, the classical model (without saturation effects) is not sufficient to predict the transient response for the speed loop. with a good precision The use of the new saturated model developed in this paper allows to obtain a more accurate simulation results of the transients that agree much better with the experimental ones under both saturated and unsaturated conditions.

\section{APPENDIX}

The values of the coefficients used in the saturation factor expression are given below.

$$
\begin{array}{ll}
\mathrm{a}=-1.1006797 & \mathrm{e}=-1.0968339 \\
\mathrm{~b}=0.45815235 & \mathrm{f}=0.4491927 \\
\mathrm{c}=-0.0655245 & \mathrm{~g}=-0.062897 \\
\mathrm{~d}=0.00437872 & \mathrm{~h}=0.0067401
\end{array}
$$

Mechanical parameters values:

$$
\mathrm{J}=0.038 \mathrm{~kg} \cdot \mathrm{m}^{2} \text { and } \mathrm{f}=0.0029 \mathrm{Nm} /(\mathrm{r} / \mathrm{s})
$$

\section{VIII.REFERENCES}

[1] P. Vas, "Generalized transient analysis of saturated a-c machines," Archiv für Electrotechnik, vol. 63, pp. 57-62, 1981.

[2] J. E. Brown, K. P. Kovacs, and P. Vas, "A method of including the effects of main flux path saturation in the generalized equations of a-c machines," IEEE Trans. Power App. syst, Vol. 102, no. 2, pp. 96-103, 1983.

[3] I. Boldea, and S. A. Nasar, "Unitary treatment of core losses and saturation in the orthogonal-axis model of electric machines," Proc. Inst. Elect. Eng., vol. 134, pt. B, pp. 355-363, 1987.

[4] T. A. Lipo, and A. Consoli, "Modeling and simulation of induction motors with saturable leakage reactances," IEEE Trans. Ind. Applicat., vol. 20, no. 1, pp. 180-189, 1984.

[5] R. D. Lorenz, and D. W. Novotny,. "Saturation effects in field-oriented induction machines," IEEE. Trans. Ind. Applicat., vol. 26, no. 2, pp. 283-289, 1990.

[6] P. Vas, and M. Alaküla, "Field-oriented control of saturated induction machines," IEEE Trans. Energy Convers., vol. 5, no. 1, pp. 218-224, 1990.

[7] B. Lemaire-Semail, F. Bouillault, and A. Razek, "Modelling of vector controlled cage induction motor with FEM," Proc. Inst. Elect. Eng., vol. 138, pt. B, no. 6, pp. 297-302, 1991.

[8] R. G. Harley, D. J. N. Limebeer, and E. Chirricozzi, "Comparative study of saturation methods in synchronous machine models," Proc. Inst. Elect. Eng., vol. 127, pt. B, no. 1, pp. 1-7, 1980.

[9] A. M. El-Serafy, A. S. Abdallah, M. K. El-Sherbiny, and E. H. Badawy, "Experimental study of the saturation and the cross magnetizing phenomenon in saturated synchronous machines," IEEE Trans. Energy Convers., vol. 3, no. 4, pp. 915-823, 1988.

[10] E. Levi, "State-space d-q axis models of saturated salient pole synchronous machines," Proc. Inst. Elect. Eng., vol. 145, pt. B, no. 3, pp. 206-216, 1998.

[11] A. Vagati, M. Pastorelli, F. Scapino, and G. Fransceschini, "Impact of cross saturation in synchronous reluctance motor of the transverselaminated type," IEEE. Trans. Ind. Applicat., vol. 36, no. 4, pp. 1039$1046,2000$.

[12] L. Xu, X. Xu, T. A. Lipo, and D. W. Novotny, "Vector control of a synchronous reluctance motor including saturation and iron loss," IEEE. Trans. Ind. Applicat., vol. 27, no. 5, pp. 977-985, 1991.

[13] M. G. Jovanovic, and R. E. Betz, "Optimal torque controller for synchronous reluctance motors," IEEE Trans. Energy Convers., vol. 14, no. 4, pp. 1088-1093, 1999.

[14] A. Vagati, M. Pastorelli, and G. Franceschini, "High-performance control of synchronous reluctance motors," IEEE. Trans. Ind. Applicat., vol. 33, no. 4, pp. 983-991, 1997.

[15] I. Boldea, D. G. Dorrell, C. B. Rasmussen, and T. J. E. Miller, "Leakage reactance saturation in induction motors," International Conference on Electrical Machines, ICEM, Espoo, Finland, vol. 1, pp. 203-207, 28-30 Aug. 2000.

[16] L. Pierrat, E. Dejaeger, and M. S. Garrido, "Models unification for the saturated synchronous machines," International conference on Evolution and modern aspects of synchronous machines, (SM100), Zürich, Switzerland, pp. 44-48, Aug. 1991 
[17] S. A. Tahan, and I. Kamwa, "A two-factor saturation model for synchronous machine with multiple rotor circuit," IEEE Trans. Energy Convers., vol. 10, no. 4, pp. 609-616, 1995.

[18] H. Kaminosono, and K. Uyeda, "New measurement of synchronous machine quantities," IEEE Trans. Power App. syst, Vol. 87, no. 11, pp. 1908-1918, 1968.

[19] G. F. T. Widger, "Representation of magnetisation curves over extensive range by rational fraction approximations," Proc. Inst. Elect. Eng., vol. 116, no. 1, pp. 156-160, 1969.

[20] A. Tounzi, F. Meibody-Tabar, and F. M. Sargos, "Vector control of a smooth stator reluctance machine taking into account saturation and damping effects," Journal de physique III, Vol. 7, no 4, pp. 909-926, 1997.

[21] T. Lubin, F. Weinachter, H. Razik, and A. Rezzoug, "Modeling and identification of a synchronous reluctance machine with a squirrel cage," $9^{\text {th }}$ International Conference on Power Electronics and Motion Control, EPE-PEMC., vol. 5, pp. 110-114, 2000.

[22] R. E. Betz, R. Lagerquist, M. Jovanovic, T. J. E. Miller, and R. H Middleton, "control of synchronous reluctance machines," IEEE. Trans. Ind. Applicat., vol. 29, no. 6, pp. 1110-1122, 1993.

\section{BIOGRAPHIES}

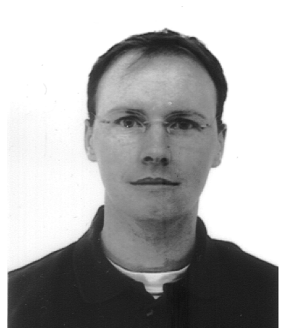

Thierry Lubin was born in Sedan, France, on January 11, 1970. He received the M. Sc. Degrees from the University of Paris 6, France. He is currently working toward the Ph.D degree in the Groupe de Recherche en Electrotechnique et Electronique de Nancy. His research interests include electrical machine, modeling and control.

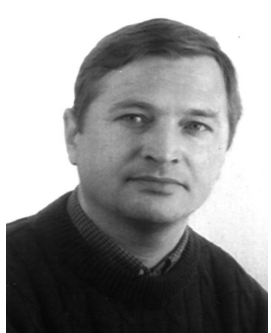

Hubert Razik (M'98) received the Ph.D. degree from the Polytechnic Institute of Lorraine in Electrical Engineering, Nancy, France, in 1991. $\mathrm{He}$ joined the Groupe de Recherche en Electrotechnique et Electronique de Nancy in 1993. He currently works as a lecturer in the University Henri Poincaré. His research interests are control of electrical machines, fuzzy logic, neural networks and genetic algorithms. $\mathrm{He}$ is a member of the IEEE Industry Applications (IAS), IEEE Industrial Electronics (IES).

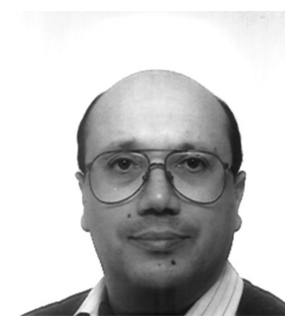

Abderrezak Rezzoug (M'79) is a Professor in Electrical Engineering at the University Henri Poincaré, Nancy, France. As the head of the Groupe de Recherche en Electrotechnique et Electronique de Nancy, his main subjects of research concern electrical machines, their identification, diagnostis and control, and superconducting applications. He is a member of IEEE. 